\title{
THE WINTER GARDEN AT CAMBRIDGE UNIVERSITY BOTANIC GARDEN
}

\author{
Tim Upson ${ }^{l}$ and Peter Kerley ${ }^{2}$
}

The history of the Winter Gardens at Cambridge University Botanic Garden is described with particular reference to the one planted in 1978-79 with discussion of the design philosophy, planting and current management practices needed to maintain this maturing garden.

\section{INTRODUCTION}

The last twenty years have seen winter gardens increasing in popularity with several major new ones created around the country, for instance at Wakehurst Place, the Sir Harold Hilliers Garden and Arboretum and the Winter Walk at Anglesey Abbey in Cambridgeshire. Of course we are here talking about gardens that utilise plants that provide winter interest, ranging from coloured stems and trunks, leaf shapes, texture and colour to flowering subjects grown for both colour and scent, rather than the traditional seaside winter garden of bandstands, palms and planted glasshouses.

Plants that provide winter colour and interest have long been grown and treasured and were admirably treated by Graham Stuart Thomas in his work Colour in the Winter Garden (Thomas 1957). The idea of creating a specific garden dedicated to enlivening the drab winter months can probably be credited, at least in contemporary times, to John Gilmour the Director of Cambridge University Botanic Garden from 1951 to 1973 (Orriss 1991).

\section{HISTORY OF THE WINTER GARDEN}

In 1951 the first Winter Garden was established in about 0.4ha ( 1 acre) of land that formed a long narrow corridor linking the eastern part of the garden, at the time undergoing development, to the existing western half of the garden (Fig. 1). Formal in design, a Yorkstone path linked together a series of planted square and rectangular beds. The garden was bordered by a yew hedge to the north and along the southern side by a demonstration of different low growing evergreen hedging material including Lonicera nitida cultivars, Euonymus japonicus 'Macrophyllus' and Buxus sempervirens, punctuated by upright conifers (Orriss 1973).

\footnotetext{
${ }^{1}$ Tim Upson is Superintendent of the Cambridge University Botanic Garden.

Address: Cambridge University Botanic Garden, Cory Lodge, Bateman Street, Cambridge, CB2 1JF

Email: upson-tmu202cam.ac.uk

${ }^{2}$ Peter Kerley is Supervisor of the Display and Demonstration Section of the Cambridge University Botanic Garden. Address: As above

Email: kerley-pk211@cam.ac.uk
} 


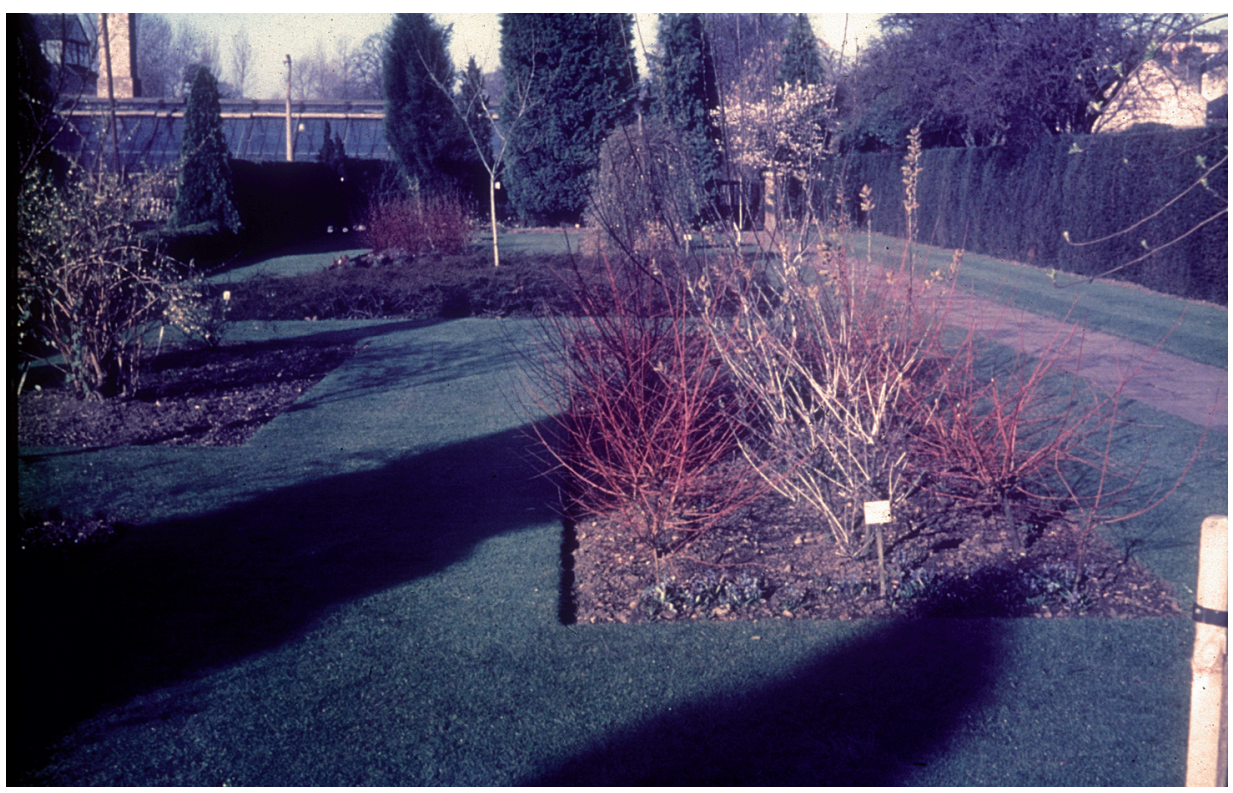

Fig. 1 The old Winter Garden. Photo: Peter Orriss.

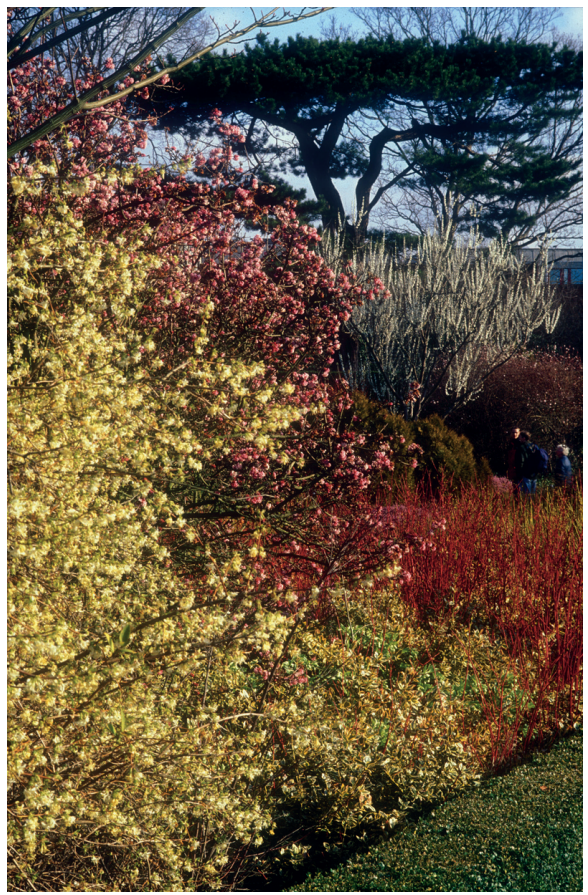

Fig. 2 The external view of the Winter Garden. Photo: Howard Rice.
In 1977 further land was needed to extend the experimental area which in part cut off this linking corridor leaving the remnant now in the private area of the garden, where it remains today. So, in 1978 Peter Orriss, Superintendent (1974-1995) and Norman Villis, Garden Supervisor (1974-1998) took the opportunity to create a new Winter Garden drawing upon a number of lessons from the original. While they utilised many of the same plants, they were used in a different and more informal style, creating drama by using large drifts of plants and ground cover as a means to reduce and simplify maintenance. Planted over the winter of $1978-79$ it is this more recent winter garden that Cambridge is famous for (Figs. 2 and 3) and has been featured in many magazines and newspapers ever since (e.g. Larkcom 1984; Buchan 1989; Marcus 1997; Thompson 2000). An authorative account on the garden's creation was 


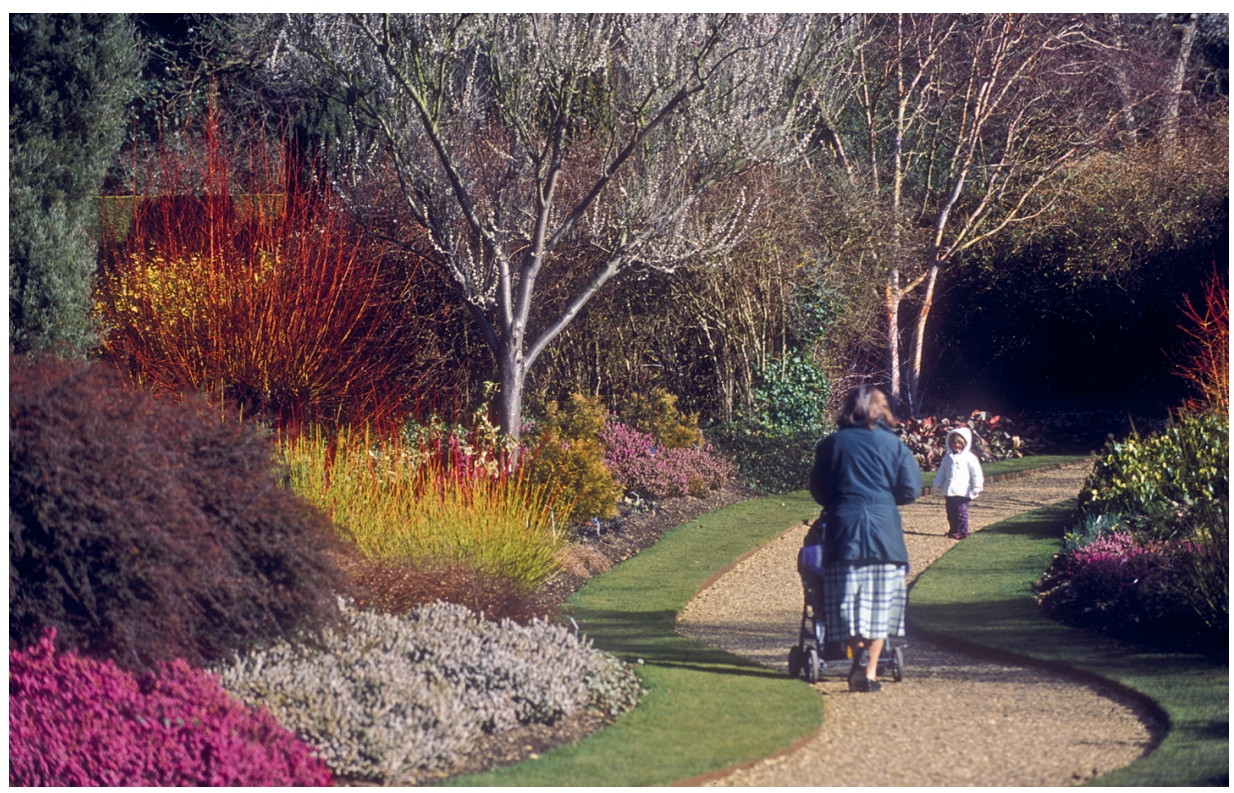

Fig. 3 The internal view of the Winter Garden. Photo: Nigel Luckhurst.

provided by Peter Orriss in 1991 (Orriss 1991). This account describes the garden just over 25 years since it was created, an opportunity to reflect on the plantings and design.

\section{DESIGN AND PLANT SELECTION}

In designing and siting the garden several key decisions were taken that ensured its success. It occupies a trapezoid shaped site, about 0.4 ha ( 1 acre) in extent and surrounded on all sides by evergreen hedges. This has created an intimate garden, protected with high hedges on three sides, with the shelter helping to capture flower scents. The hedges also provide a backdrop against which the main plantings are composed and can be viewed (Fig. 3). Along the southern side the hedges have deliberately been kept low so as to capture every available ray of winter sunlight. The various hedging species used are punctuated by upright conifers, a feature taken from the original Winter Garden. The clever use of the low winter sun has proved an essential ingredient in the success of the plantings. The gently meandering central path naturally takes visitors through the garden and on one side it is possible to view the plantings with the sun shining directly on them, whilst on the other the stems, flowers and trees are backlit, which is particularly effective in the late afternoon. This clever use of sunlight brings a new dimension to the garden and its plants. The siting of Acer griseum, the Paperbark Maple, was clearly no mistake when the flaking, curling cinnamon coloured bark can be seen glowing in the afternoon sun. The Wineberry, Rubus phoenicolasius (Fig. 4) was also sited so that the reddish, 
glandular-bristly stems are picked out and highlighted by the winter sun, whilst nearby the waxy pale-yellow petals of Chimonanthus praecox become translucent in this light.

Cambridge is flat and lacks undulations and so another key decision was to landscape the site. The central path was excavated so it dips down to a low point before rising again as it leaves the garden, leading the eye through. The spoil was used to create banks on either side so many of the plantings are viewed at eye-level or looking slightly up from the central path. From the external path running past the southern side one gets a completely different view looking down into the garden and across to the beds on the far side. Small valleys cutting diagonally into the banks at either end create more diversity. Originally, these were enriched with peat to grow acid loving plants such as rhododendrons although this proved unsuccessful, probably due to the exposed dry conditions early on. These changes in levels and undulation are relatively minor, usually not much more than 1.5 metres, but the effect achieved appears much greater than this and adds much to the charm and success of the garden.

The framework of the garden was created by the strategic placement of deciduous trees and conifers. Flowering cherries provide flower colour, possibly the most spectacular being Prunus davidiana 'Alba', the pure white flowers borne in mid-late February, a sensation when viewed against a clear blue sky. A great favourite is a multi-stemmed specimen of Betula albosinensis var. septentrionalis which in Cambridge only forms a

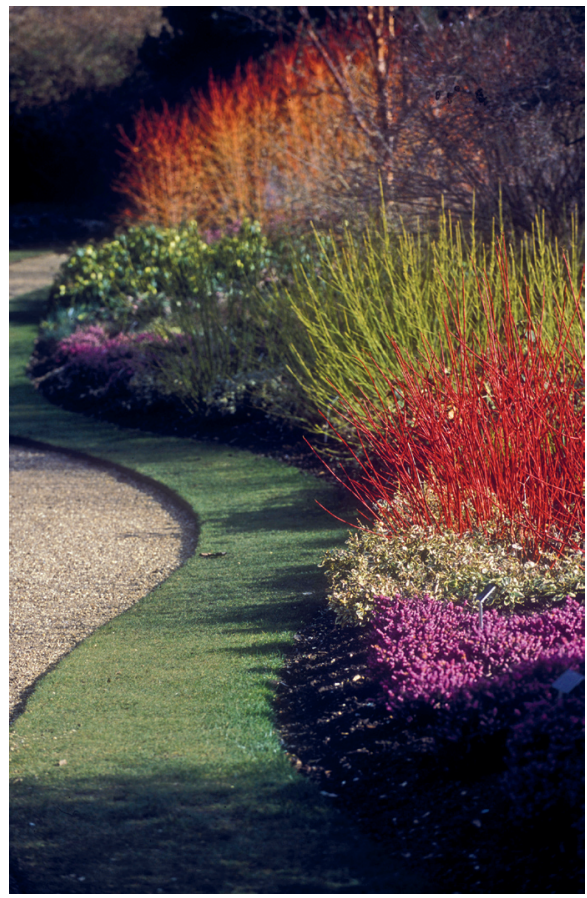

Fig. 5 Coloured dogwood stems. Photo: Nigel Luckhurst.

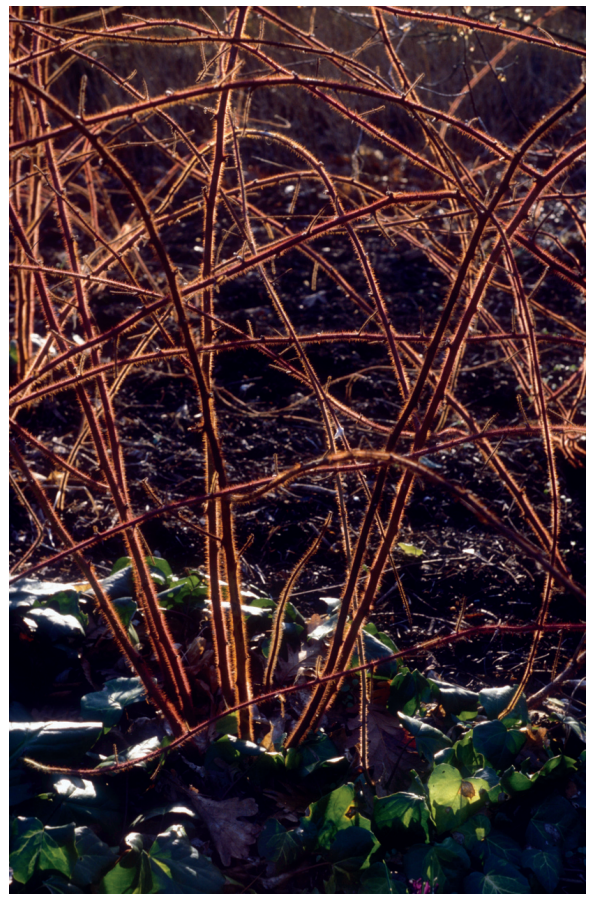

Fig. 4 Rubus phoenicolasius. Photo: Tim Upson. Luckhurst. 
small tree, the grey-pinkish bark contrasting with the dark green of a Leyland Cypress hedge behind. The columnar shape of the various conifers gives strong vertical accents as well as evergreen colour. Several cultivars of Chamaecyparis lawsoniana are used, 'Winston Churchill' for its rich golden-yellow foliage, 'Pelt's Blue' for its narrowly conical form and blue-grey foliage (replacing a group of 'Pembury Blue' that became overmature) and 'Wisselii' a plant of great architectural interest, with short crowded branchlets, particularly attractive when covered with its numerous red strobili in spring. The dense narrow columnar habits of Juniperus virginiana 'Burkii' and Chamaecyparis lawsoniana 'Kilmacurragh' are planted to contrast with the horizontal branches of Juniperus 'Grey Owl'. The red fruits of the ornamental apple, Malus 'Red Sentinel' which are usually maintained into the new year and the yellow-green coloured stems of Cornus sericea 'Flaviramea' complete this planting combination.

A major feature are the bold sweeping drifts of plants used throughout the garden with plantings of coloured stems giving the greatest effect. Dominating these plantings are the dogwoods, the red stems of Cornus alba 'Sibirica' and the greenish-yellow of C. sericea 'Flaviramea' (Fig. 5) have been used to create rivers of colour flowing across the garden. Underplanted with Euonymus fortunei 'Silver Queen' the creamy-white and green variegated evergreen leaves contrast, and hence enhance the colour of the dogwood stems. The effect is spectacular and it is these plants with coloured stems that provide the mainstay of the display providing bold splashes of colour from November right through to early March when they receive their annual pruning to ensure new young vigorous stems that have the brightest colour. The use of such bold splashes of colour was deliberate, and although not always liked by all, it certainly has the intended effect of brightening even the darkest winter's day.

Equally as spectacular as the Cornus is a clump of Salix alba 'Britzensis', grown for its bright orange-yellow stems, sited to form a major focal point viewed as visitors enter the garden. These plants are pruned annually, not to ground level as is usual with other cultivars, but to a point about a metre from the ground so the young coloured stems emerge from a 'knobbly trunk' full of character. This creates the effect of lifting the mass of coloured stems to a higher sight line bringing further diversity of effect. A more recent and successful planting, also forming a focal point, is that of Cornus sanguinea 'Midwinter Fire'. The youngest stems are bright yellow-scarlet, fading to a light yellow as they mature, sited for maximum effect against the dark evergreen, even sombre, foliage of Arbutus unedo 'Rubra'. This Cornus does not withstand the annual pruning regime used on the other species and instead is cut on a three year cycle. A potential problem that arises is that the youngest and hence brightest coloured stems become located at the top of the plant and the effect is lessened, at least when close up. This has been overcome by pruning the clump of plants at different levels, close to ground level for some and to higher points for others. The effect when viewed from a distance is of the brightest stems rising continuously from ground level to the top of the tallest plants now nearly three metres tall.

The other genus giving us good garden plants with coloured stems are brambles, Rubus spp. Best known are those grown for the waxy white bloom on the stems 
which are most vivid on year old stems (the bloom being rubbed away on older stems) which are therefore pruned annually to ground level. The most spectacular is the ghostly Rubus biflorus which produces long white thorny arching stems. This requires the plants to be sited away from paths where the stems can reach their natural length and thus avoid the unnecessary shortening of the stems. Less vigorous and more suitable for smaller gardens is Rubus thibetanus 'Silver Fern' which also has a white bloom to the bristly stems and in our case is used to contrast with the purple-black stems of Cornus alba 'Kesselringii'. The lower growing Rubus cockburnianus 'Goldenvale' is used to trail down a bank underplanted with the Winter Aconite, Eranthis hyemalis, providing a bright yellow carpet beneath. Perhaps the most unusual and choice species is Rubus niveus, which bears mahogany-brown stems that gleam most brightly when wet.

One of the best combinations involving Rubus in the garden also provided a lesson in the dynamics of plants and gardens and the need for timely interventions. The white stems of $R$. biflorus were planted in a semi-circle around Viburnum $\times$ bodnantense 'Dawn' both contrasting with the copper-yellow flowers of Hamamelis $\times$ intermedia 'Jelena'. However, by the late 1990's this combination had been lost. The Rubus readily layers itself and over time had moved away from its original position, appearing amongst the surrounding plantings and with the mother plants dying away. This combination has now been re-created, with new plants of the Rubus in the original position thriving after renewing the soil and digging in plenty of organic matter (Fig. 6).

Planted between are clumps of shrubs grown predominantly for flower colour, scent

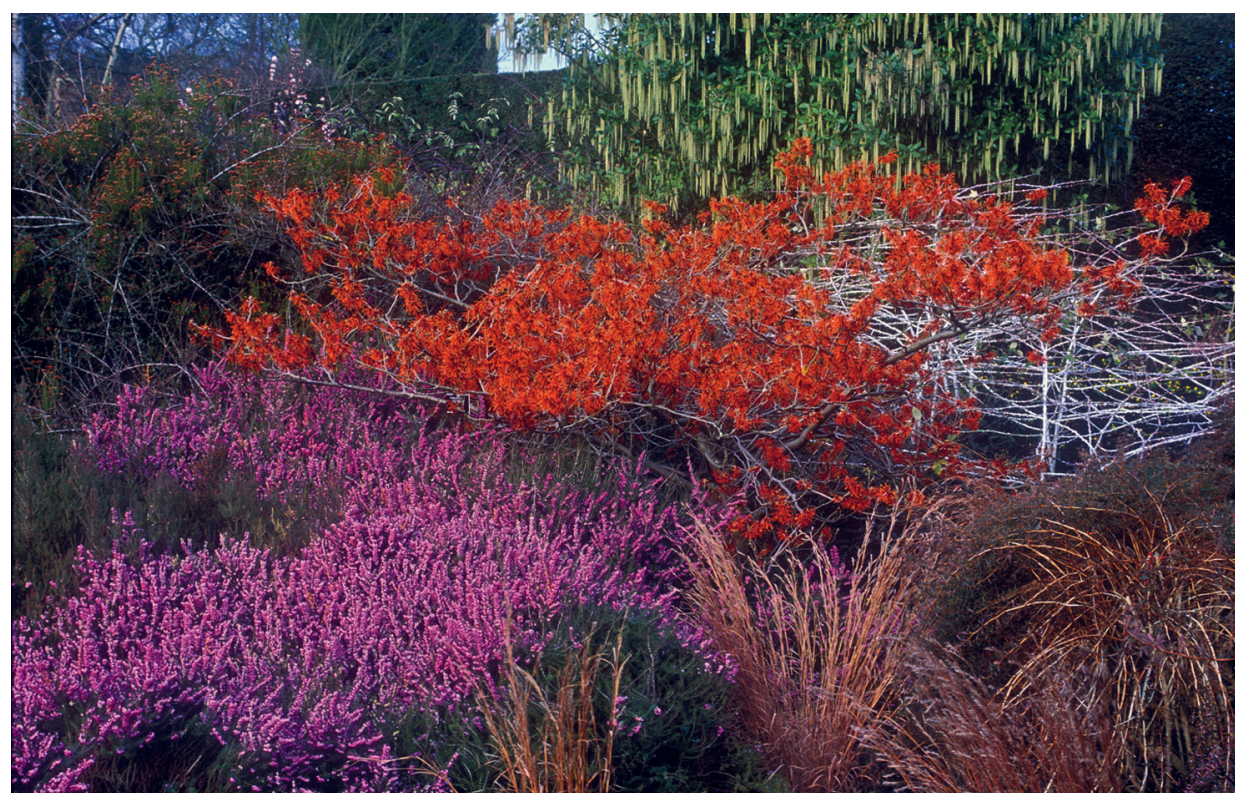

Fig. 6 Hamamelis 'Jelena' and Rubus bicolor. Photo: Howard Rice. 
and ground cover. A particularly good performer is Lonicera $\times$ purpusii, valued for its scented flowers borne profusely over a long period of time. Clumps of this superb hybrid are located at each entrance and on mild still days, one literally walks through a wall of scent. Several more choice species feature with L. setifera and L. elisae giving late winter colour. Equally floriferous is Viburnum farreri and its hybrid with $V$. grandiflorum, $V . \times$ bodnantense, first raised at the Royal Botanic Garden, Edinburgh in 1933 and later at Bodnant, in North Wales in 1935 and commemorated in the epithet. All three of the named cultivars are grown of which 'Charles Lamont', the Edinburgh-raised cultivar, is considered quite superb. It is interesting to reflect on the biology and role of these flowering plants in the British winter garden. Most are actually early spring flowering subjects coming from parts of the world where the winters are cold and harsh with spring coming very quickly. In our relatively mild Atlantic climate these plants are stimulated into flower during mild periods. With winters becoming increasingly mild those flowering shrubs capable of producing a long succession of flowers will often flower continuously over the winter period. In the 1980's the colder winters meant these plants were far more sporadic in flowering and often did not peak until late February and early March. In recent years one might judge the garden to be at its peak of flowering and colour at the end of January and beginning of February, a further reflection of recent changes in weather patterns. Perhaps the most extreme example of a winter flowering subject reacting to the changing climate is Prunus incisa 'February Pink'. As its name suggests the pale pink flowers would normally appear in February but in the last five years it has regularly come into bloom in November.

Another equally profuse flowering shrub is the evergreen Viburnum tinus from the Mediterranean region which thrives on the top of the dry and sunny banks. This species would naturally flower over the winter in its native environment, the hot dry summers being the dormant period. It has clearly responded to the mild winters here flowering continuously from autumn to spring. An unusual evergreen shrub, Garrya $\times$ issaquahensis is grown for its long greyish-green catkins, tinged with red borne during February and March. It is a hybrid between the more commonly grown Garrya elliptica and G. fremontii and was received as seed from Seattle in 1962 where this outstanding hybrid was first raised. Taxa of Mahonia also provide a combination of attractive evergreen foliage with flower. The popular shrubby species $M$. japonica bears lax racemes of lemon-yellow flowers with a lily-of-the valley scent and is planted where this can be enjoyed. Contrasting in habit is the erect hybrid, M. × media 'Winter Sun', the dense erect racemes of bright yellow flowers which resembles a shuttlecock provide early winter colour from November until Christmas. Whilst Colletia paradoxa bears almond scented white flowers in autumn and early winter, its main winter interest is in the highly unusual flat triangular spines.

Low growing shrubs were planted in large drifts and remain an important feature today. Cotoneaster horizontalis was selected for the architectural effect of its herring-bone patterned branches, which are particularly attractive on a frosty morning. Several cultivars of Berberis wilsoniae have been used forming thorny humps, the small leaves 
turning attractive shades of russet-brown, enhanced in colder weather. Symphoricarpos $\times$ chenaultii ' Hancock', a dwarf spreading groundcover, is now pruned to ground level on an annual basis, the stems arching attractively to 400-500mm high. Several lime-tolerant winter flowering heathers are grown including Erica carnea and E. $\times$ darleyensis. They have proved themselves to be reliable performers even in our dry conditions and if replaced every 10 years or so a profusion of flowers is guaranteed. The many cultivars available allow the creation of drifts of pinks, whites and purples. Erica terminalis, a summer flowering species, is grown for its brown coloured seed heads that are attractively picked out by winter frost.

\section{USE OF BULBS}

Bulbous and other plants with underground storage organs are an essential element in any winter garden. From early spring they bring much needed colour and include some of the best-loved winter flowering plants, such as snowdrops. Initially they did not thrive on the dry sunny site, but as the garden has matured suitable planting niches have been created. The best effect has been obtained by massing them into drifts or by using the larger snowdrops for their greater impact amongst other plantings. The best performers include the Common Snowdrop, Galanthus nivalis (including the double form 'Flore Pleno') and perhaps the most admired is G. 'S. Arnott'. This large and vigorous snowdrop now forms large drifts at the entrance, the white flowers grouped together with another great favourite, Helleborus orientalis, the Lenten Rose. Both enjoy the shade offered by the adjacent hedge. In dry sunny spots Iris lazica and I. unguicularis with their deep purplish-blue flowers is always a welcome sight and the linear leaves are contrasted with those of Epimedium perralderianum. A classic combination at its best in late February is the grouping of the pure blue flowered Scilla sibirica grown beneath the pale yellow flowers of Forsythia giraldiana. The Scilla has more recently been used under a large drift of the white variegated Ivy, Hedera helix 'Glacier' planted to create a crescent shaped drift alongside the white flowered $E . \times$ darleyensis 'Silberschmelze', both emanating from the base of the flowering cherry, Prunus $\times$ subhirtella 'Autumnalis Rosea'. Having the largest leaves of any Ivy, Hedera colchica 'Sulphur Heart' with its dark-green foliage splashed with a golden variegation is used as groundcover, and also produces upright stems bearing the spherical umbels of flowers and fruits which are spectacular when covered in hoar frost.

It is interesting to note that many of the bulbous plantings have disappeared or become entirely vegetative as the surrounding plantings of shrubs have shaded them out. Such bulbous plantings maybe need to be treated as ephemerals in this situation, dying out over time as the garden matures, compared to a meadow situation where the bulbs will generally persist given the correct mowing regime. Some bulbous plantings are now treated in this way. When large shrubs are pruned leaving gaps, bulbs such as Narcissus $\times$ monochromus 'February Gold' have been used to provide a splash of colour until, after several years, the regrowth shades them out. 


\section{HERBACEOUS PLANTINGS}

Herbaceous plantings also have their place in the Winter Garden. Grasses such as Anemanthele lessoniana (more commonly sold under the incorrect name Stipa arundinacea), a tufted grass, is used for its architectural form, others for their long lasting flower spikes. Particularly effective is Miscanthus sinensis 'Purpureus', a low growing form to about a metre, which in the autumn bears russet-brown leaves with a purplish tinge and are retained on the stalks until the following spring and do not fall and litter the ground which is a common problem with many Miscanthus. In contrast the large oval leathery leaves of Bergenia species and cultivars are used principally for leaf size, shape and colour, although several also provide early spring flower. With its purplish-red winter foliage Bergenia 'Bressingham Ruby' is planted to contrast with the russet brown linear leaves of Carex flagellifera, whilst Bergenia $\times$ smithii 'Sunningdale' is quite superb, the rich-reddish leathery leaves combined and contrasted with the white flowers and short needle-like foliage of $E . \times$ darleyensis 'Silberschmelze'. Whilst the leaves of $B$. crassifolia can be less tidy than other taxa of bergenia, they are a good foil to other plantings and the pale pink flowers are a delightful harbinger of spring.

\section{RECENT MANAGEMENT ISSUES}

In describing some of the combinations created it is worth reflecting on some of the issues that have arisen as the garden has matured over the last 25 years. We have cited several examples of how the dynamics have changed over time and the need to recognise and respond to this. One problem that has become more apparent in recent years is scale, particularly with some of the conifers and deciduous trees. In the case of conifers many have become too tall and broad, dominating the surrounding plantings, while others have begun to lose their tight habits. We are now in the process of gradually removing some of the larger plants and replanting. In other cases such as a maturing Acer capillipes the spreading crown had become too dominant, casting a dense shade over an ever increasing area. Beneath, Jasminum nudiflorum used as a flowering ground cover had ceased to bloom well, with only a few of the wonderful bright yellow flowers borne at the end of the stems. In such an intimate garden that relies on the performance of all plants, problems of this type soon start to detract from the overall plantings. In this case, with the tree affecting so many of the associated plantings the only option was to remove the tree. However, its strategic position required that the area still needed height and hence a new specimen has been replanted.

From these experiences it has become clear that a different strategy in managing the trees in this situation is required. Rather than allowing them to mature, as would be the case in other areas of the garden, they need replacing on a 20-25 year cycle, so as to retain the appropriate scale of planting and avoiding the excessive shading of other plantings. This has another advantage as some trees are grown for their attractive trunks, 
including the Snakebark Maples such as the Acer capillipes where the green and white striated bark is most vibrant in young plants.

Since the planting of the Winter Garden, many new plants providing winter interest have become available, whilst a whole range of others have been used in new ways and combinations in other Gardens. One of the best new plants to become available is Daphne bholua 'Jacqueline Postill' and a group is now planted at the entrance so visitors can enjoy their scented flowers. Other plants often used in other winter gardens for foliage and architectural effect include plants such as Aralia elata, bamboos, Phormium cultivars and Eucalyptus spp. Somehow such plants would not fit with the style and planting schemes of the Cambridge Winter Garden and we have avoided such introductions.

\section{CONCLUSION}

We hope the Winter Garden stands as an example of good design and horticultural practice but its importance to the wider running of the garden has developed greatly in recent years. Boosting visitor numbers is essential to survival, particularly during relatively quiet times of the gardening year. The Winter Garden provides a focus not only to promote more winter visitors but also to encourage the enjoyment and charms of gardens and plants at this time of year. In no other season can a garden change so much and so quickly. It is full of flowers and scent during mild winter spells, sparkling in the late afternoon sun, stems and trunks shining brightly after rain or with frost and snow emphasising the architecture of the plants.

\section{ACKNOWLEDGEMENTS}

We wish to acknowledge the creators of the Winter Garden, Peter Orriss and Norman Villis, whose combination of writings and personal accounts have provided much of the material for this piece.

\section{REFERENCES}

BUCHAN, U. (1989). Refusing to Hibernate. Country Life, January 19 1989: 60-63.

LARKCOM, J. (1984). The New Winter Garden at Cambridge. The Garden, 109(10): 389-394.

MARCUS, C. (1997). Winter Wonderland. The English Garden. November/December 1997: 28-31.

ORRISS, P.T. (1973). The Winter Garden at Cambridge. J. Roy. Hort. Soc. XCVIII (1): 8-13.

ORRISS, P.T. (1991). A Winter Garden in Cambridge. pp. 78-85. Plants \& Gardens, Brooklyn Botanic Garden Record.

THOMAS, G.S. (1957). Colour in the Winter Garden. 220 pp. Phoenix House Ltd, London.

THOMPSON, E. (2000). Frozen Beauty. The Sunday Telegraph Magazine, 30 January 2000: 45-47. 